\title{
The Therapeutic Alliance with Parents and their Children Working Through a Relational Trauma in the Family
}

\author{
Maria Lisa Gilson ${ }^{1}$ D $\cdot$ Angela Abela ${ }^{1}$
}

Accepted: 31 August 2021 / Published online: 19 October 2021

(c) The Author(s), under exclusive licence to Springer Science+Business Media, LLC, part of Springer Nature 2021

\begin{abstract}
This study is about how a therapeutic alliance is created and maintained with parents and their children working through a relational trauma. A case study design with narrative analysis as a method of research (Riessman, 2008) and a narrative approach of storying stories, inspired by McCormack (2000), is used. The participants of this study are the parents and their four children, aged between 14 and 5 years, and their systemic therapist. Rich data on the therapeutic alliance is gathered through, two live-family session observations and seven interviews, six of which were with the family members, and a twopart interview held with their therapist. Results show that the way of being of the therapist, including her ability to be intuitive and self-reflexive, and her ability to keep manoeuvrability in conversation and hold neutrality support her to connect with all the family. Creating conjoint and separate therapeutic spaces, using a creative play-based approach and navigating an alliance with the school and medical professionals, were important suggestions for practice in the field. Additionally, collaborating with parents, and balancing the benefits and drawbacks of involving children to make therapy meaningful for all, are also suggested. Specific recommendations for engagement with siblings of the identified-problem child are elicited. The strength of this study is that children's voices, along with those of their parents' and their systemic therapist are reported. Suggestions for practice to support children and their families who are working through a relational trauma are brought forward.
\end{abstract}

Keywords Therapeutic alliance $\cdot$ Children in therapy $\cdot$ Adolescent-parent conflict $\cdot$ Relational trauma $\cdot$ Narrative case-study

\section{Introduction}

In systemic practice the therapeutic context is a "multi-actor setting" (Escudero, 2016, p.2), that involves an "expanded therapeutic alliance" (Sprenkle \& Blow, 2004, p.124). A recent meta-analysis confirms that strong alliances in family therapy are linked to favourable therapeutic outcomes (Friedlander et al., 2018). Different to individual therapy, a systemic psychotherapist needs to manage the conjoint setting of family sessions. Escudero and Friedlander (2017), suggest that "the conjoint context is particularly challenging for clients as well as for therapists" (p.6). The need for research on systemic therapeutic alliance is noted by various authors (Balestra, 2017; Simon, 2018).

This study explores the therapeutic alliance, when the family therapist is working with parents and their children

Maria Lisa Gilson

marialisagilson@gmail.com

1 Department of Family Studies, University of Malta, Msida, Malta who are experiencing a relational trauma. In this study the definition of relational trauma put forward by Alexander (2013) will help us make sense of this complex relationship. This trauma develops after repeated difficult interpersonal experiences between the parent and the child, often occurring during crucial developmental periods. The therapeutic alliance building with parents and their children who have experienced these difficulties is considered to be a research gap by Escudero and Friedlander (2017). Given that the clients' perceptions, in this case, those of the parents and their children, regarding the systemic therapeutic alliance will be taken into account, the study will also address the need for further research in this area (Perkins et al., 2019).

We value the importance of attachment as a theoretical framework with regards to the building of a therapeutic alliance between therapist and children and parents. In line with an attachment narrative framework, as proposed by Dallos and Vetere (2009), we believed that the narratives that the participants shared with us offered us a window into their experiences of attachment. In this respect, we were keen to listen to the stories they held about their 
connections, dependencies and experiences of trust in their relationships.

A social constructivist epistemological stance (Schwandt, 2014) has been adopted given that the family members' and their therapist's experience of the therapeutic alliance are understood as occurring in relation to a wider network of relationships. According to this stance an individual learns by building on knowledge that already exists and by interpreting existing knowledge in new ways. In the same way the therapeutic relationship is influenced by previous attachment experiences and previous attachment experiences can help interpret the therapeutic relationship.

\section{Literature Review}

In light of the above research gap, a succinct literature review will highlight studies on the engagement by the therapist with parents and young family members during systemic therapy. The experiences of family members in family therapy are presented, as well as the experiences of therapists working with children and adolescents and their parents.

\section{Building a Collaborative Relationship with the Parents}

Often the parents present to the clinic strongly believing that their main problem is their child's emotional or behavioural manifestations (Andolfi, 2016; O'Reilly, 2015). In these circumstances, the challenge of the systemic therapist is to find ways to work with parents that help them shift their position from blaming the child. This process of negotiating responsibility may leave parents feeling inadvertently criticised and blamed for relational dysfunctions occurring in the family (O'Reilly \& Lester, 2016). Several authors have highlighted that parents should be approached with respect, with an understanding that they generally try their best to support their children, and with sensitivity that they too might be grappling with past relational traumas (Brown, 2008, Dallos \& Vetere, 2009; O'Reilly \& Lester, 2016; Sammut Scerri et al., 2017).

The few studies that have elicited the parents' experience of family therapy (Brown, 2008; Sheridan et al., 2010; Thompson et al., 2007) show that they value the calming, composed and fair stance held by the therapist especially during moments where the family are in conflict. Parents also seem to appreciate gaining awareness of their own vulnerabilities and improving their parenting (Thompson et al., 2007).

\section{Engaging Young Family Members in Family Therapy}

Studies highlight the importance of a playful approach to foster good alliances with young family members in family sessions (Desmond et al., 2015; Willis et al., 2014). A meta-analysis on youth alliance-outcome relations, carried out by Shirk et al. (2011), shows that creating and maintaining a positive alliance with youths predicts successful outcomes. Children also want to feel connected to their therapist and this is strengthened when their voices are validated by the therapist and family (Lobatto, 2002). A systemic practitioner must also keep in mind that young family members rarely initiate their own therapeutic process. Moreover, in families where there is trauma, if the child perceives that their caregivers are the reason they are in therapy, therapeutic-alliance building may be more of a challenge (DeVet et al., 2003). Additionally when children experience trauma in caregiving relationships, their perception of themselves, and others as trustworthy may become compromised (Cloitre et al., 2002; Van Nieuwenhove \& Meganck, 2019). This can lead to difficulties in establishing a therapeutic relationship, even though this in itself could help them revise their past trauma (Pearlman $\&$ Courtois, 2005).

Engaging adolescents in family therapy can be even more challenging, as they may be reluctant to be in therapy. This can be understood within the context of their developmental needs for differentiation from parents and other adult carers (Eltz et al., 1995). Nonetheless creating a collaborative relationship with adolescents is possible (Diamond \& Liddle, 1999). This is further supported in the results of a qualitative study by Thompson et al. (2007), that explored the process of engaging high-risk youth, aged between 12 and 18, and their parents, in a homebased family therapy intervention. Results showed that the youths that were interviewed appreciated the therapists' active listening skills, authenticity, their calm presence, impartial position and sense of humour. In the study the youths also shared that family therapy had helped them relate better to their families as they could listen to each other more, and patterns of arguing slowly shifted to constructive communication (Thompson et al., 2007).

\section{The Therapist's Experience of Working with Children and Adolescents and their Parents}

The only paper that we found on the therapists' perspectives on the therapeutic alliance with children and adolescents is the study carried out by Campbell and Simmonds (2011). In this study the five therapists that were interviewed reflected on the benefits that a positive alliance 
with the parents can have on alliance development with children (Campbell \& Simmonds, 2011). The therapists also noted that having the family attend together for the first session can help in establishing a sense of trust and safety (Campbell \& Simmonds, 2011). This way of working is also suggested in Chapter 6 in the work of Sammut Scerri et al. (2017) regarding working systemically with parents and children in the context of trauma.

The therapists in Campbell and Simmonds (2011) study also reflect on the relevance of the therapists' self-awareness in this delicate work with children and their parents. Furthermore they added, that to be genuinely present for the client, the therapist needs to have worked through their own unresolved childhood or adolescence issues. The authors note that while the therapists' past woundedness can be valuable for client empathy, unless these themes have been processed the alliance may be undermined as the therapist may experience emotional exhaustion.

\section{Research Question}

This study will attempt to answer the following question: What are the stories of the parents and their children (ages 5 to 14), and their therapist about how a systemic therapist creates and maintains a therapeutic alliance with a family working through a relational trauma?

\section{Methodology}

\section{Research Design: A Narrative Case Study}

A case study research was deemed most suitable, as this method has been recognised "to capture, describe and analyse evidence of complex processes" (McLeod, 2010, p.9). More specifically, an intrinsic case research design (Stake, 2005) was adopted because the focus is on the uniqueness of the case itself. Stake (2005) elaborates that distinguishing between intrinsic case study from instrumental can be challenging, because there is combined purpose in both designs and some generalization from intrinsic case studies is still possible. The chosen therapeutic process merited this focus because of the intrinsic value that the family presented, particularly the four siblings in different developmental stages concurrently being involved in family sessions. At the same time, the choice of this research design allowed for insights and suggestions for practice which may be helpful to family therapists working in similar contexts.

\section{Participants}

The study was carried out with a Maltese family. Malta is a member of the European Union. It is a small island in the Mediterranean Sea. The Maltese live in a close-knit community, where the unity among family members is important (Abela, 2016).

\section{Criteria for Selecting the Family}

The criteria below had to be met for a family to be selected.

- They voluntarily sought Family Therapy at the Foundation for Social Welfare Services (FSWS) and consented to participate in the study. The FSWS is a service-hub that offers free social welfare services to families and individuals.

- The systemic psychotherapist/s following the family consented to participate in this study.

- They have children ( $<16$ years-old), who will be participating in the sessions.

- The family's presenting issue relates to a relational trauma (as defined in the Introduction section).

\section{Background Information about the Participants, the Presenting Issue}

A table with basic information about the participants and a brief explanation of the presenting issue are found below. See Table 1.

The presenting issue is intense sibling rivalry that escalated to the point that one threw a knife towards the other and a conflictual relationship between the 14-year old, Gianni, and his parents, in the context of physical abuse by the father towards his son and a history of intergenerational physical abuse from father to son.

\section{Ethical Considerations}

Ethical approval was sought from the University of Malta, Department of Family Studies-, the Faculty for Social Wellbeing-, and the FSWS- Research Ethics Committee.

\section{Recruitment Procedure}

Once written approval was received from the Ethics Boards, we contacted the Family Therapy Team and provided them with an information letter. This letter outlined the aims of the study, our contacts and the salient characteristics of participants needed for this study. The letter was also an invitation to all systemic psychotherapists within the team, who 
Table 1 Basic Information About Participants

\begin{tabular}{|c|c|c|c|}
\hline Pseudonym & Role & Age & Brief description \\
\hline- & The father & $45-50$ & $\begin{array}{l}\text { Main bread-winner, works manual job, who experiences difficulty in relating with his son. } \\
\text { In the course of therapy he puts forward the belief that his son has inherited the intracta- } \\
\text { ble traits of his own father, who was threatening towards him }\end{array}$ \\
\hline- & The mother & $40-45$ & $\begin{array}{l}\text { Main caregiver, stay-at-home mum, who experienced her own mother to be very critical } \\
\text { such that she lacks confidence in her ability to mother }\end{array}$ \\
\hline Gianni & First-born child & 14 & $\begin{array}{l}\text { He has been diagnosed with Attention Deficit Hyperactivity Disorder (ADHD) and Oppo- } \\
\text { sitional Defiant Disorder (ODD), currently followed by a psychiatrist }\end{array}$ \\
\hline Ian & Second-born child & 11 & He experiences severe bouts of medically unexplained symptoms \\
\hline May & Third-born child & 7 & - \\
\hline Judy & Fourth-born child & 5 & - \\
\hline- & The systemic psychotherapist & $45-50$ & $\begin{array}{l}\text { A female warranted practitioner, two-years experience, has a passion for working with } \\
\text { children }\end{array}$ \\
\hline
\end{tabular}

were allocated a family who fit the criteria for participation. If interested to participate, the systemic psychotherapist needed to opt-in by sending an email of interest or by calling us. A detailed information sheet was then provided to the systemic psychotherapist and a consent form was filled out.

The family were informed about the research during the first call the systemic psychotherapist had with the family. A script with information was provided. If interested to participate, the adults in the family were encouraged to introduce this research to their children. Families that were interested in participating, opted-in by contacting us directly. Following this, an information meeting with the family was carried out and consent was discussed. Information sheets were used and signed consent from the adults and assent forms from the children were gained.

\section{Data Collection}

The data collection in case study research is extensive and draws on multiple sources of information (Creswell, 2012). We collected data in the following sequential phases:

- Two live-family session observations- the third and the sixth family sessions were chosen for the observations. The choice of sessions was informed by Friedlander et al.'s (2018) contention that analysis of the third to the sixth session give a good indication for early alliance. The sessions were audio-recorded and transcribed by the authors. More so, the authors kept hand-written notes of significant moments during the observations.

- Brief interviews with the children, and use of drawing

- A one-time interview with the parents

- A two-part interview with the systemic psychotherapist

All interviews were transcribed verbatim.

\section{Data Analysis}

To analyse the various data collected we followed a number of steps that are explained below:

- When analysing the two therapy session transcripts, we used the System for Observing Family Therapy Alliance (SOFTA) (Friedlander et al., 2006) instrument, as a theoretical exploratory framework. This tool guided us in eliciting the themes related to a number of processes related to the building of the therapeutic alliance between the therapist and the various members of the family.

- We then shifted our focus to the various interview transcriptions and the transcribed therapy sessions and engaged in a process referred to by McCormack (2004) as "storying stories" (p. 219). To do this we first looked at the individual interview transcripts and the two therapy sessions, through multiple lenses, which include, active listening, narrative processes, use of language, context, and moments, and then we used "the views highlighted by these lenses to write interpretive stories" (McCormack, 2000, p. 282). In the process of constructing the story we also explored the content of what was told in the interviews, the sequence and coherence of the stories, the tone and emotions used by the participants, and we took note of the themes invoked in each story (McCormack, 2000, 2004; Riessman, 2008).

- To remain authentic to the voices of the participants, we did a cross-sectional analysis of the stories where we were attentive to similarities, differences, recurrent themes and common patterns. We organised the little stories we collected into one plot and we interspersed uninterrupted text from the different transcripts along our story, to highlight the voices of the participants. We also include snippets of observations that are written in the present tense, that help retain vivacity to elicit the readers experience of being there (Geertz, 1988). The 
stories the younger children said about their drawings were also taken into account. Therefore we became interested in how the themes elicited in the observations, the interviews and the drawings overlapped and how they contributed in creating a multi-faceted understanding of the participants' experiences. This back and forth process allowed for multiple narrative truths (Freeman, 2003) that are recounted in the narrative. By so doing we could construct a rich interpretive story which is found in the findings section and which we hoped would provide an answer to our research question.

- Such a narrative approach gives importance to feedback from the participants (McCormack, 2000) by returning the story to them and asking about how their views have been represented. In view of this, the story was sent to the systemic psychotherapist to elicit her feedback. Initially we also planned on meeting the family to elicit their views of the narrative. Nevertheless because of COVID-19 restrictions and the ensuing limited face-toface access of the family members with the therapist, we were concerned that the family would not have the necessary support should the writing in some way overwhelm them. In the circumstances, we therefore relied on the feedback obtained by the family therapist who engaged in the process and who ascertained that the story that was constructed was in tune with the different experiences of the various family members and of herself.

Following the Findings section and in line with Elliott's (2005) approach to narrative analysis, in the Discussion section, we look at the findings in more depth and attempt to answer the research question by highlighting how the stories told help us understand how a therapeutic alliance is created and maintained with a family working through a relational trauma.

\section{Methods of Verification}

The measures of credibility, dependability, transferability and confirmability proposed by Guba (1981) were kept in mind throughout the different stages of the research to ascertain the trustworthiness of the study. The eight criteria for quality in systemic practitioner research, proposed by Simon (2018), namely, Systemic practice, Methodology, Situatedness, Relational Ethics, Relational Aesthetics, Reflexivity, Coherence, and Contributions, were also adhered to enhance the quality of this study.

The triangulation of sources involving the views of the family members, the therapist and the observer also ensured credibility and confirmability (Dallos \& Vetere, 2005). The use of different data collection methods, including live family session observations, interviews with the therapist, the parents and the children, and drawings with the younger children (see section above on Data Collection), provided access to more credible data and compensated for the limitations of the individual methods. The peer review of the second author who acted as a supervisor in this study further enhanced the credibility of the data. The sharing of the narrative (discussed further above) with the systemic therapist, as a form of respondent validation, also served as a method of verification.

\section{Results}

\section{Setting the Scene Through the Eyes of the Researchers}

We are observing from behind the one-way mirror. The therapist is sitting between the two boys. 'Like instruments in an orchestra, there is the percussion, the trombone... They all have different tunes but when played together they can create lovely harmonies. How can you be different and still get along?' she asks them. She is mitigating a relationship that escalated to the point where Ian threw a knife in Gianni's direction, prompting Gianni to call the National Helpline for support. It is this incident that led to the referral for Family Therapy.

The parents are present. Judy is asking for more water for her painting. May has stopped colouring in her rainbow and she has turned her attention towards the therapist, 'Can I tell you a story?' she asks. Before getting a reply she continues, 'Last Saturday Gianni wanted to fix the bike and Papa said 'No!' and Gianni was upset, and Judy, me, and Mama were getting ready, then Gianni came and he rang the doorbell, and Mama saw his face, and told us, 'He looks mad!' 'I am the bad luck in this family!' says Gianni. May undisturbed by the comment leans forward in her seat, 'He went upstairs and he started to get mad at Mama. At everyone. He was also kicking, like this look, the stool.'

'Is it time yet?! The Youth Club opens in 5 minutes!' says Gianni who appears to be losing his calm.

'We are done when we are done!' replies the father. 'I didn't finish my story...' May reiterates. 'After a bit he grabbed a, a, a, a fork, and Mama was washing the dishes and he was like, like this, almost wanting to put it in her shoulder!' (Observation Session 2, January 2020) 


\section{Presenting Issue: An Intergenerational Perspective}

Gianni (14-year old), is diagnosed with ADHD and ODD. The therapist describes him as emotionally mature. She also said that he speaks about 'not feeling loved in the family'. In the interview he described himself as being 'always angry, at school, at home, everywhere'.

The therapist explained that Gianni craves attention from his father. The parents acknowledged that the father is at times physical with Gianni. In the interview Gianni also mentioned that he harbours a sense of fear of his father.

Gianni: I feel scared at times because if he loses his temper, he is stronger than me, so if he had to punch me, I'm done.

The plot thickens when the therapist reflects that in her work with the family she needs to constantly hold the parents' emotional baggage. In my (first author) encounter with the parents, they spoke about reconnecting to their younger selves during therapy;

Mother: she has even asked me questions that have helped me reflect on past experiences. Today I realise that this is probably why I am tired, as all my life I have had to take care of others.

The therapist is mindful of the mother's early vulner-

abilities, in fact she notes;

Therapist: her mother was very demanding, she used to put her down a lot, so as an adult she needs to be reassured that she is doing her best, that she is a good enough Mum.

The father is also grateful for the space to reflect on his early relationship with his father;

Father: she helped me think differently about the similarities I see between Gianni and my father, she invited me for sessions alone to discuss this in detail. When I had told other professionals, they had told me, 'don't compare them, every person is different', whereas she told me, 'how are you comparing them?'

\section{The Children and their Parents' Stories of their Experience of Family Sessions}

Judy (5-year old) answered the question, "What is family therapy?" by choosing to paint a few of her favourite things, she drew; 'a chocolate chip cookie', 'popcorn', and 'a dinosaur doing a handstand'. See Fig. 1. She said that she loves 'painting' in sessions and that someone who wants to become a family therapist needs to learn to 'be nice'.

Furthermore, May's (7-year old) response was that family therapy is, 'where kids and grown-ups who have problems go'. What she likes best in sessions are crafts and games. She thinks someone who wants to become a family therapist needs to, 'learn to be kind, and to help others.'

May is described by the therapist as, 'a mother to her brothers', and a child who is able to 'sugar coat reality' with fantasy.

Therapist speaking about May: Everything has flowers, rainbows and smiley faces.

When May was prompted to draw what family therapy is, she drew Fig. 2.

When May finished her drawing, the first author who was with her asked,

Researcher: What's happening in your picture?

May: Ganni is speaking and Mama and Papa don't have time to speak, and Ganni is shouting a lot, Ian is hiding behind the curtain, and you are looking out of the window

Researcher: What about you?
Fig. 1 Judy's drawing, 'What is family therapy?'

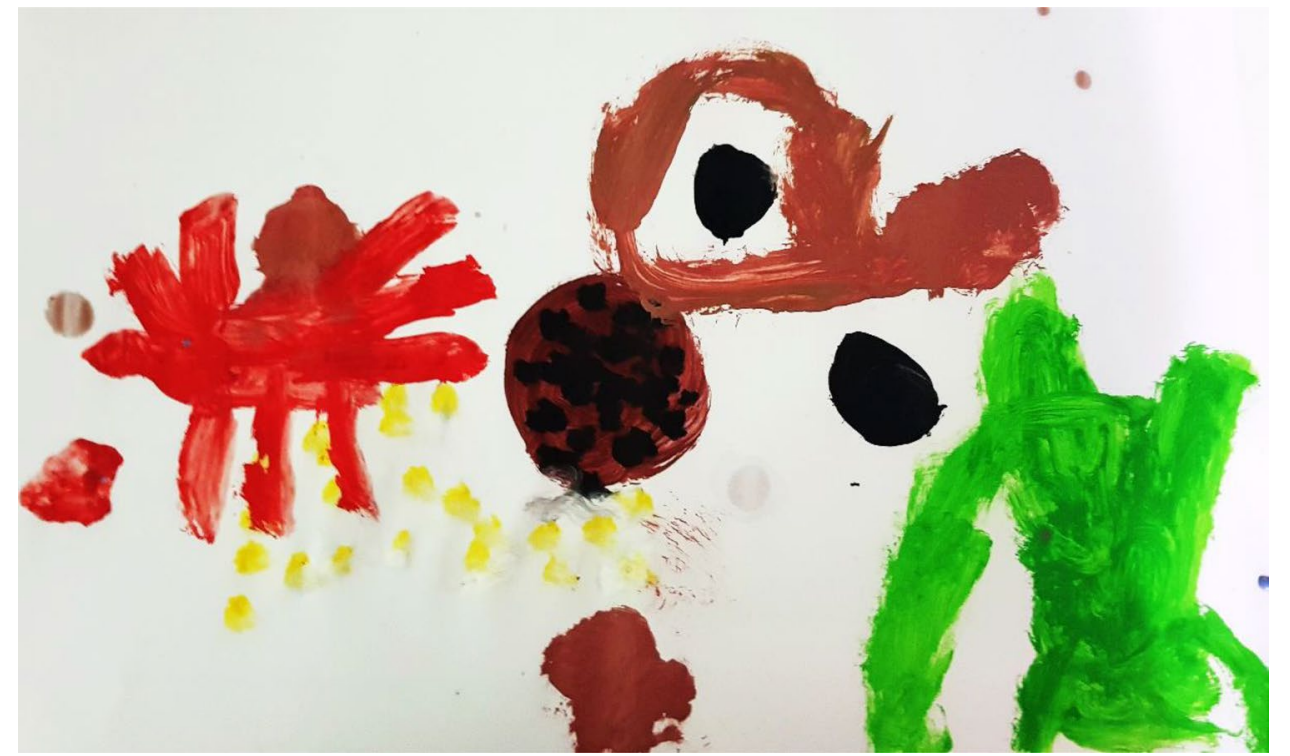


Fig. 2 May's drawing: 'What is family therapy?'

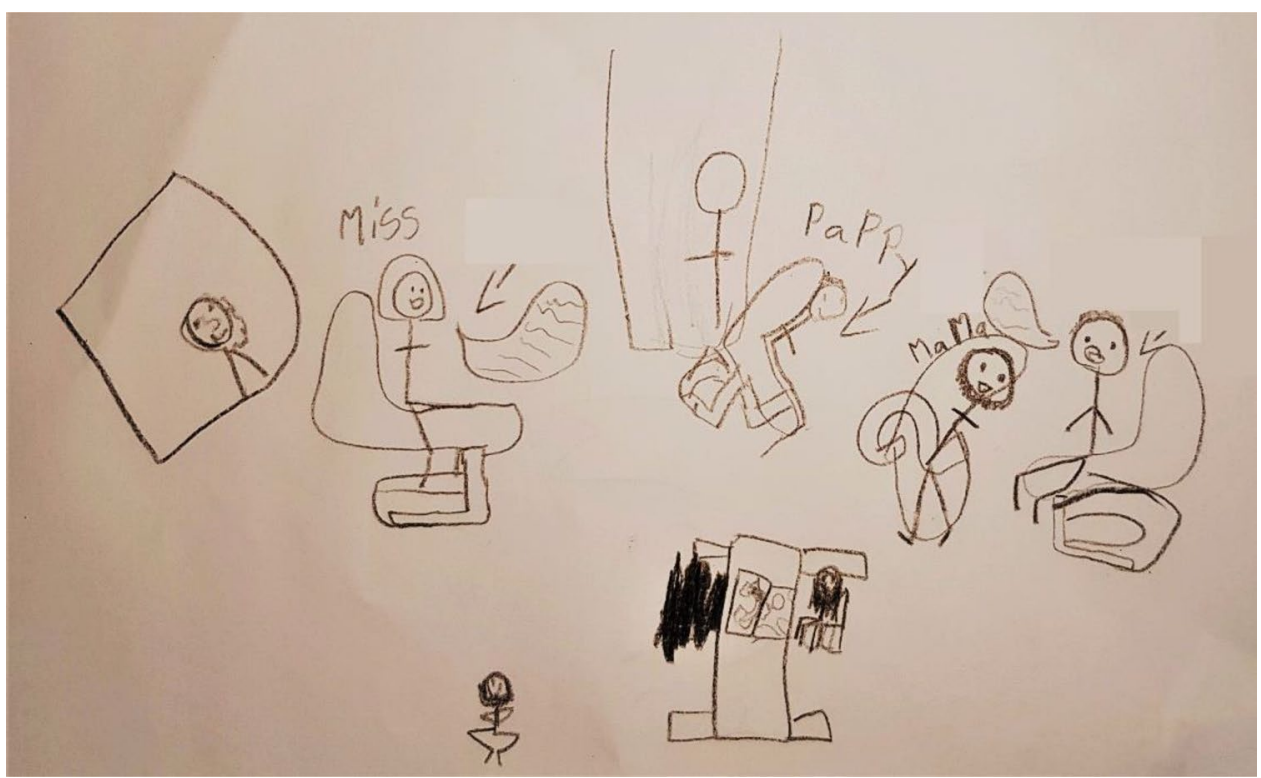

May: I'm just quiet, listening and colouring

Researcher: How are you feeling in that moment?

May: Sad, because Ganni is shouting, lying, and he doesn't give me a chance to say the truth

During the debriefing stage of the interview, May asked if she could change something in her drawing;

May: I want to remove myself, and I am going to place me meditating (she scribbles over the image of herself in the drawing, and draws herself meditating)

Researcher: You'd like to be meditating

May: I won't be listening and I will be calm and no one disturbs like when I am in my dream world

Researcher: your dream world...

May: Yes I want to be there but I want to feel like I am not there, that I am in my dream world

On the other hand, Ian's (11-year old) response was;

Ian: family therapy means being happy. It helps people become happier with each other.

Ian also likes games most in sessions. He thinks someone who wants to become a family therapist needs, 'to be calm and they shouldn't do sessions that are just talking'. He is described by the therapist as 'boiling with emotions like a pressure cooker. He is fascinated with dinosaurs.' He has a strong 'sense of injustice that makes him very angry to the point that he feels somatic symptoms, head aches, stomach pain, it is all emotional.' When prompted to draw what family therapy is, Ian drew Fig. 3.

It was interesting that during the interview with the therapist, she had commented on Ian's process by saying;

Therapist: family therapy might be the place to make peace with the dinosaur... I have this image of a dinosaur who is creating havoc in his stomach, almost like ripping at the meat inside his stomach, he needs to come out.

The mother explained during her interview that there are times when he misses weeks of school because of stomach complaints. Further adding;

Mother: I was left speechless that in one of the sessions, just after he had spoken up about what annoys him at home, he came and told me in my ear, 'the pain has subsided.'

Gianni appreciates that family therapy can improve how a family communicates. He also believes that someone who wants to become a family therapist should know the following.

Gianni: someone who is angry, is either bullying others or is being bullied. Then you also need to see what is happening at home. Then the situation starts to get better.

Furthermore, the parents described family therapy as;

Mother: support, it is like we could not figure out what we need to do and she is helping us.

Father: we are learning a different way of dealing, and being, with our children. Before we were feeling lost, so having someone in our life who can draw our attention to issues we might be overseeing is important.

\section{The Therapeutic Alliance is an Emotional Connection}

To understand better the alliance the family members have with their therapist, we asked the family members what they like most about her.

Judy: she is nice, she lets me use her toys.

May: she is always kind. She gives a chance to everybody... when I speak she listens and she does not listen to anyone else. 
Fig. 3 Ian's drawing, 'What is family therapy?

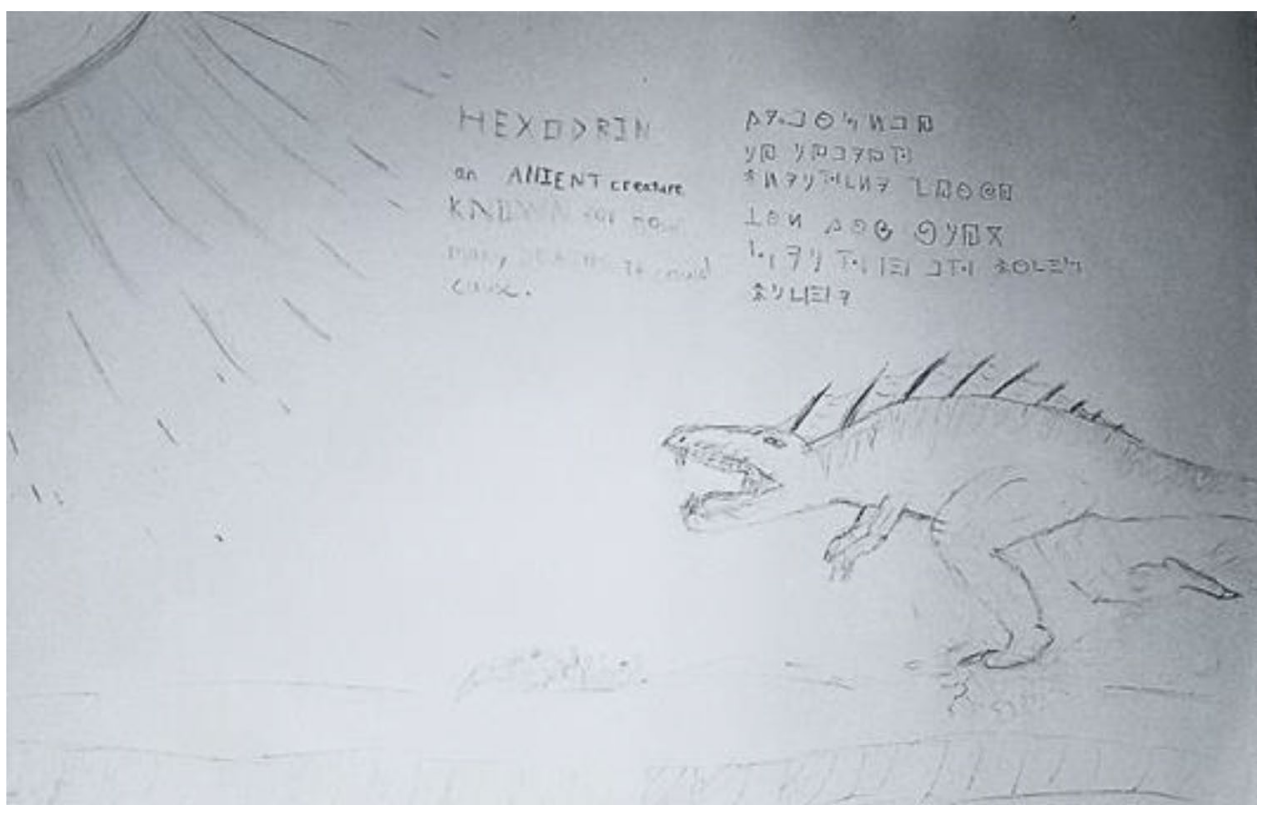

Ian adds that what he likes most about the therapist is the feeling of being understood.

Ian: she makes me happy. I feel understood

Researcher: Tell me more about how you feel understood

Ian: I just feel it. I just feel she understands me

Gianni appreciates being listened to.

Gianni: I start speaking and she listens, then we reason it out together, then she changes what I said into her own words and she says it in a way that my parents can understand it.

Researcher: How well do you think the therapist understands you?

Gianni: bull's eye, I am not joking.

The theme mentioned by Ian and Gianni of feeling understood was also echoed in the interview with the parents.

Mother: A sense of going somewhere where I know I'm going to feel comfortable and understood.

Father: I get a sense of being with family, we feel comfortable with her, she gets our perspective.

The mother adds that her favourite session was one which she attended alone with the children.

Mother: they gave each other space to talk, I don't know if she played some magic on us, when we are at home they all speak over each other. It was surreal... I could observe them all.

The parents appreciated that they were involved in the therapeutic process and spoke about the differences between this experience where all the family is involved to previous experiences of individual psychological support.
Father: it's one way listening to the sound of one instrument, and another listening to a symphony. She has taken a holistic approach.

\section{The Engagement Process}

The therapist emphasised that a therapeutic engagement process is dependent on the therapist's ability to find a common language with the family, 'you have to speak their language whatever it is.'

The parents were frank that they were initially skeptical about the referral for family services. They both agreed that it was the father's involvement in the process that secured the engagement.

Mother: He started at zero, then when he accepted to come for a session and I saw him involved, it filled me with courage.

The father spoke about his initial expectation to be judged as a parent. The mother added that the fact that the therapist could see them regularly also helped in the engagement process.

\section{A Creative and Collaborative Approach}

A snippet from our observation notes depicts the therapist's approach during family sessions.

All the family members are present. 'We have a story about a garden full of birds today,' introduces the therapist. May and Judy are fiddling about with bird cut-outs that are dispersed on the table. Ian is excited and grabs the colours. The parents are tagging along. 
'Pick a bird cut-out each, I brought the colours' says the therapist. Gianni replies, 'I don't like drawing!' The therapist smiles and adds, 'you can be a white bird, what do you think?' All the six birds are given a colour. 'While you colour, I will read the story', says the therapist. (Observation 1, September 2019)

The mother admits she was not sure her husband would be comfortable to join in drawing activities. The father remarked on how engaged the children are when the therapist introduces an art activity. Father: it is amazing how the children would be drawing, then because they feel relaxed, they also open up and start talking. She barely asks them direct questions they join in and start to talk.

\section{Want to Participate More}

The younger family members want to participate in a more meaningful manner.

Researcher to Judy: Which one was your favourite session?

Judy: all of them I didn't like but one. I like the one May, mum and me were alone, we played a lot.

Researcher: What was different in the other sessions?

Judy: Gianni all the time speaks.

This was also noted in one of the observation sessions where May had assertively stood up from her seat and said;

May (addressing the therapist): Gianni, Gianni, always about Gianni. He only talks and we get to be silent.

Ian also mentioned this in his interview;

Ian: I don't like it when my brother takes most of the time, I don't get a chance to talk as much. Sometimes I feel like I want to participate more.

Also Ian and May, both remarked that they feel uncomfortable during arguments between their parents and their brother, as they feel a strong need to say the truth when there are lies. Ian said the least thing he enjoys in sessions is 'when we stay saying what Gianni did and he denies it.' While May said when there is an argument, she feels sad and she would want to speak up and say, 'it's a lie.' At the same time, she rated how comfortable she feels in session, 5 out of 10 , adding that, she feels like a 5 because she does not like to have to hear lies.

\section{Managing the Alliance between the Adolescent and the Parent}

The therapist said she often feels 'caught in between' the adolescent and the parent. She even explains that it is sometimes painful for her to witness the way Gianni's feelings are dismissed by his parents in sessions. The therapist recalls that in a particular session Gianni told the mother that he feels he has a good relationship with her. She further recalls that the mother had replied,

Mother: I don't know how you are saying that you have a good relationship with me. She told him, 'I feel uneasy the minute you walk into the house.'

Reflecting on this interaction the therapist shares,

Therapist: I felt like somebody had stabbed me with a dagger. My heart ached, literally. He gave her his heart and she almost told him, 'Stay away'. It physically hurt me! At the same time I also connect with her. So, on one hand, I'm feeling her sense of helplessness, as she wants to protect herself and her three other children. On the other hand, she has this boy too and part of her loves him and part of her wants to reject him.

The therapist then explains how she therapeutically followed up this session by offering a session to the mother.

Therapist: we spoke about her childhood and how parentified she was when she was little, I worked with her inner child. She added that she favours a collaborative approach with the parents and approaches them as experts in the lives of their children. She demonstrates her approach by telling us that she would ask the parents, for instance;

Therapist: If this situation had to happen again, what can you do differently? If you had a friend who is going through the same thing, what would you tell him? When they tell me, 'what should we do?' I tell them, 'I believe you have the strength to do something like that,' or 'you have the resources inside you to make it work.'

The therapist explains how she feels like she is walking a tight rope in managing the relationship between the adolescent and the parents.

Therapist: Gianni told me, that he feels hurt when he perceives me taking his parents' side in the argument. At the same time if the parents perceive me inclining towards Gianni's perception of reality, I risk losing their trust.

\section{The Process Informs you who to Invite}

The therapist elaborated that it is the process that informs her decisions of who to invite. She said when she notices that a family member needs more support she sets up individual sessions. In initial meetings she would explain her ways of working, for instance;

Therapist: at times I will invite different family members, it doesn't mean that I do not care about your story, it could be just that they need some more support. 


\section{Collaboration with School and Medical Professionals}

The father appreciated the therapist's multi-perspective approach.

Father: we are a family, we have different perspectives. She did not target him as the problem, she considered the whole family. She is not only concerned about what happens in the therapy room, she also monitors his progress at school too. That makes a difference.

The systemic therapist is working collaboratively with the school counsellor. She refers to the collaboration as a, 'sounding board', and she adds that it helps her, 'thicken the perspective.' She recalls a meeting she had with Gianni's school counsellor, his psychiatrist and the parents, and shared her frustration in knowing that they planned on assessing Gianni for ASD. She concedes that collaboration with professionals offering individual support to family members, increases the complexity of the work because of relational dynamics that need to be negotiated among professionals.

Therapist: It is still worth it, I wouldn't work in isolation, even though it's more complex. It sometimes helps fill up missing gaps.

\section{The Hope for Change}

We were interested in asking the family members what change they hope to see when the therapy comes to an end. The three younger children had a common answer of wanting their brother's behaviour to change. At the same time Gianni is hoping for more family unity. The mother hoped for a sense of normality. Whereas the father hopes that he would have learnt different ways of how he can deal with his son's behaviour.

\section{The Different Identities of the Therapist that Help her to Connect}

The therapist reflected that to be able to work with children and adolescents, 'you need to be in contact with your inner child.' The therapist adds that having been able to process her childhood experiences in therapy, and her identity as a mother help her empathise and connect with the parents.

\section{Discussion}

On the basis of the narrative which we constructed in the preceding section, we will now discuss the art and skills needed when creating and maintaining a therapeutic alliance, with both parents and children, when working through a relational trauma in the family, and the challenges this entails.

\section{Systemic Thinking a Conceptual Resource that Secures Connection}

Traumatic experiences affect the entire family (Dallos \& Vetere, 2009), and thus a systemic way of working can allow the different stories of the family to emerge. The ability to hold a position of uncertainty in the face of competing truths, that are very often prevalent in families that experience inter-relational difficulties, offers the systemic therapist a vantage point for creating simultaneous alliances with different family members. In the narrative, the parents and Gianni, are both confident of the therapist's interpretation of their reality. The therapist's ability to hold these multiple viewpoints, not in opposition but in complementary relationships, is in line with a major epistemological revision, typical of the second phase of systemic practice (Onnis, 2016). This study suggests that the constructivist epistemological stance is a conceptual resource, and tool, that offers grounding to the creation of multiple alliances with families' working through trauma.

\section{The 'Way of Being' of the Therapist is key for Engagement}

The children appreciated the therapist's disposition which they perceived as kind and including everyone. The centrality of the therapist's way of being to the therapeutic relationship has been highlighted by Fife et al. (2014). This study adds to this field, as findings show that it is the therapist's disposition that helped the family members connect to her. Other attributes that were noted by the parents were, her readiness to listen attentively, to manage conversations, and her ease in being almost part of the family.

The therapist's ability to actively elicit aspects of her clients' lives that hold potential without challenging the negative identities too soon also helps her to connect. For instance, when she needs to challenge the parents, she does this in a manner that helps her transmit the message, that she believes they have what it takes to act and reflect differently. Thus a belief in the resilience of family members helps the systemic therapist relate to families.

The results of this study show that other therapists' skills are important when working with parents and their children when there is trauma in the family.

\section{The Ability to be Intuitive}

The findings of this study show that it is important that therapists develop a sense of awareness of the feelings that 
families stir within themselves, as this in turn affects how they position themselves in relation to the family.

Systemic therapists can then let their intuitive sense guide their therapeutic decision making, and this can consolidate relationships. For instance, when the therapist met the family and assessed the needs of the family, she had an intuition that they need containment and invited them to attend weekly. The mother notes that when the therapist offered to meet so soon, she felt a sense of reassurance that she was not alone anymore, and this helped her to bond with the therapist. In another instance, the therapist reflects that when she witnessed Gianni's attempts to get close to his mother being turned down, she experienced a sharp pain in her chest. She acknowledged that this could be her affective resonance (Jensen, 2012) to Gianni's pain. She used this intuition, both, to strengthen her alliance with Gianni, as she could understand how real his pain is, and to connect with the mother. The therapist refrained from shaming the mother for her difficulty in responding effectively towards her son. Instead the therapist followed her intuition and offered the mother individual space to support her in processing what had happened in the session. This session helped her strengthen the allegiance with the mother as it gave her the opportunity to listen to the mother's childhood stories, that had an underlining theme of 'being not good enough'. The therapist could understand that when Gianni challenges the mother, he triggers within her these past traumas which demobilise her. The results of this study highlight the importance that systemic therapists' follow their intuitive sense to inform clinical decisions. These decisions often help to strengthen alliances.

\section{The Ability to be Self-reflexive}

In the narrative, the therapist reflects that when working with this family, she taps into different self-identities. She mentions that her childhood experiences help her to connect with children. It is through these experiences that the therapist can allow a sense of creativity to emanate in the process and this permits connection with the children. Nonetheless, the therapist's personal journey of revisiting her own childhood struggles in therapy and her identity as a mother, also guide her when working with the parents. The importance of the therapist's self-reflection to guide therapeutic intention and decision-making aligns to the work of McIlwaine and O'Sullivan (2015).

\section{The Ability to Keep Manoeuvrability in the Dialogical Space}

The therapist's ability to both take the lead and to pace, the multi-layered stories that come alive in the therapeutic conversation, sustains the emotional connections of the various family members with her. She was observed embracing the role as a manager of conversation, a stance initially suggested by (Anderson \& Goolishian, 1988). This directive yet neutral stance in the management of conversations is noticed by Gianni.

The systemic therapist's ability of swiftly shifting from one family member to another in a short interval of time was also noticed. This is illustrated in the observation-snippet where the therapist is seen having a conversation with the two boys, yet at the same time she is attuned to Judy who is asking for water for her painting, and concurrently she shifts her attention to May who wants to tell her a story. This example shows that a position of curiosity about the family's reality enhances the therapist's manoeuvrability, as she attunes to the spontaneous unfolding of the process and builds alliances.

\section{The Ability to Hold Neutrality}

The therapist says that it is often a challenge to balance the adolescent's perspective and the parental concerns. This has been recognised as a unique challenge for family therapists working with parents and adolescents (Sheridan et al., 2010). When caught in situations calling for opposing tendencies in the alliance, she holds neutrality by setting up separate therapeutic spaces. For instance, when May disclosed that Gianni was violent towards the mother, Gianni felt blamed and complained about missing the youth group meeting implying a sense of disengagement to the process. In this situation the therapist diffused this impasse by setting individual sessions with the adolescent and with the parents, an approach suggested by (Benítez et al., 2019). This helps her ensure safety and take a stand against violence. It also allows the therapist to empathise with the opposing attitudes of the parents-adolescent conflict, helping each part to reflect on the point of view of the other. This attention to multiple realities, appears to help the therapist move away from becoming the opponent of the parent or the adolescent.

\section{Consolidating Alliances by Creating Conjoint and Separate Spaces}

In the initial session the therapist invites all the family and she informs them that at times she will hold individual or sub-group sessions, along family work. The fact that she addresses this early in the process supports her in maintaining a good working alliance in the mid-phase of the therapeutic process. The therapist notes that due to safety issues much of the work so far has been in supporting Gianni and the parents. Nonetheless she still holds the entire family in mind and she occasionally slots in sessions with the younger children so as to maintain her alliance with them. 
The integration of conjoint and separate therapeutic spaces gives the therapist the opportunity to engage more closely with some members, this in turn helps her to maintain the expanded alliance that is needed when all the family are present. For instance, she invites the mother and her daughters for a 'girls' session'. In the session she uses nondirective play to connect with May and Judy. At the same time this session helps her build allegiance with the mother by highlighting an 'us'/ 'we' category. In this manner, the therapist meets the mother as an equal, the explicit similarity is their gender, nonetheless implicitly, they are both leaders of their own family, adults. Therefore, separate therapeutic spaces can consolidate alliances in creative ways.

\section{A Creative Play-based Approach Helps in Building Alliances}

The use of therapeutic stories, metaphors, drawing and free play are interwoven in the therapeutic process. The therapist appears to adopt a metaphor, that allows a safe distance to the exploration of themes that prevail in the family dynamics. To address themes relating to competition and lack of co-operation, the therapist refers to instruments in an orchestra that collectively create lovely melodies. She also reads to the family a story of birds who need to give each other space to create a pleasant atmosphere in a garden. The therapist believes that a creative approach supports her to establish a common focus in conjoint sessions and this supports the alliances. She believes that these activities help families to think differently about core issues, while respecting the developmental age of the younger family members. This technique of processing themes that could link the split positions aligns to the work of Escudero et al. (2012).

\section{Balancing the Benefits and Drawbacks of Involving Children}

The systemic practitioner needs to balance the benefits of having all children involved. Some of the children's replies to the interview show that being a witness to hostile conversations between their parents and their adolescent brother is causing them distress. They all mentioned that most of the session talk-time is about Gianni's behaviour, and they wish to participate more. May and Ian also said that when there is disagreement, they feel compelled to say their view of things. However, they are uncomfortable about being the ones to speak up. Children's desire to be included meaningfully is a long-standing call for practice and was initially reported by Stith et al. (1996). If the children continue to experience distressing feelings, the alliance with the therapist may be threatened.
Another instance in the narrative that shows that the therapist needs to weigh out whether having all the family in the room benefits the children is depicted in May's drawing. This drawing can be interpreted as representative of children's struggles of being present in therapy when there is conflict in the family. May told the first author, that when conflict arises, she would rather visit her dream world. She quickly scribbled over the figure that represented her and drew another figure meditating, probably suggesting that it is almost unbearable for her to be in the room and thus chose to escape. This is an important reminder that the systemic practitioner needs to actively protect the children from problem-saturated conversations in sessions where parents and their children are present.

\section{Making Therapy Meaningful for All}

The systemic practitioner needs to withstand the family's pressures of 'fixing' the identified child and find ways of inviting exploration into other dysfunctional relational patterns (Brown, 2008). When this occurs siblings of the identified-problem child can find new meanings to the therapeutic process and alliances can be strengthened. A shift in focus could support the children to grasp a sense that therapy could support their family in multiple ways. When we asked Gianni's siblings what they hope will change when therapy ends, they said Gianni's behaviour. This is an indication that they have a linear understanding of therapy which positions them as side-lined participants in the therapeutic process.

The therapeutic process could become more meaningful for May and Ian if their personal struggles are also dealt with. For instance, Ian's drawing sheds light on the fact that his somatic difficulties stand in the shadow of Gianni's externalising behaviour. The dinosaur he draws can be interpreted as representative of the inner turmoil experienced by children who somatise because of relational difficulties in their family. Following a session where Ian found the courage to speak about how he feels in the family, he had told his mother that his stomach pain had gone. This is an indication that family therapy could help Ian ease out the tensions that he stores in his body. Additionally, May's bold move asking to be heard is also noteworthy, 'he only talks we get to be silent'. This call almost echoes the position of the mother in the family. The mother and May seem to be caught in a circular dysfunctional relational pattern. The mother feels tired amidst conflictual family relationships and withdraws to a child position, this in turn drives May into a parentified role, where she becomes the mother of her brothers and her mother's protector. The more the mother loses her voice as an adult, the more May is pushed into adult responsibilities, replaying the same reality the mother experienced in her own childhood. This role reversal is seen in the case study when May takes the stand to inform the therapist that Gianni had 
attacked the mother with a fork. The connection the therapist shares with the mother, that serves as a means of empowerment, and the connection the therapist has with May, that serves as a model of good mothering, can help reshape the alliance between the mother and the daughter. Thus, when working with parents and children where there is trauma, this shift towards the multi-layered reality of difficulties in family relationships can support alliances among the family members, siblings can be engaged more meaningfully in the therapeutic process and the identified-problem child is less singled out. In turn, alliances of the family members towards the therapist are strengthened. This work is more typical of the middle-stage of therapy, and the connection and trust that is formed with the therapist in the engagement stage can propel this gradual shift in focus.

\section{Showing Compassion Towards Parents}

The parents spoke about the ineffectiveness of individual psychological support, especially because they were cut off from the therapeutic process and left in the dark on how best to parent their children. In the present therapeutic process they are aware that they are at the centre of the approach, and they are grateful for being met with compassion and warmth. The collaborative stance embraced by the therapist helps in valuing the parents as equal partners in the relationship (Anderson \& Goolishian, 1988). The therapist adopts a non-expert position, and she speaks and listens in ways that demonstrate her desire to maintain a close working relationship. She seeks to validate the parents' pain and to empower them, and this helps her keep connected. She is aware of their intergenerational vulnerabilities and seeks to nurture their inner child. This helps to facilitate the development of empathy (McIlwaine \& O'Sullivan, 2015) and it also consolidates her relationship with them. For instance, the father said that he appreciated that the therapist did not dismiss his experience of likening his son's personality to that of his father. He said she listened attentively to the similarities that he perceives, and she also asked him questions that helped him reflect further. He says this drew him into the process and has helped him to start making links on how his unresolved relationship with his father is impeding the connection with his son.

The therapist's ability to invite the parents to move back and think allows her to stay connected with them in the therapeutic process. For instance, she invites the parents to think about what they would tell a friend who is going through the same situation. The reassuring therapeutic relationship has offered comfort to the parents and this is helping them regain trust in themselves in being able to manage their family difficulties. The father did not shy away from saying that he expected to be blamed, and that he was disheartened that this process would be any different to their other experiences of therapy. In fact, he did not join the family for the first few sessions. Nonetheless the therapist dared to invite him and the parents both confirmed that once the father got involved, the therapeutic alliance and process became stronger. This is a reminder of the importance of creating alliances with all family members, as the silent member could be a key person to strengthen the allegiance with the family system.

\section{Navigating an Alliance with the School and the Mental Health Service}

The parents and the adolescent, both appreciate the efforts of the therapist to collaborate with the school and medical professionals. The therapist values the collaboration yet at the same time she acknowledges that navigating a working relationship with other professionals can at times be a struggle. This is also acknowledged in the work of Berryhill and Vennum (2015), who suggest that similar to the engagement process with clients, building a therapeutic alliance with school personnel can have its' challenges. Nevertheless, a general context of mutual respect between different professionals and the family, is conducive to therapeutic change. This is also echoed in this study, as the therapist states that despite the difficulties she still prioritises collaboration.

In the face of opposing discourse to explanations of family realities, for example working from a trauma-informed perspective versus a medical model, based on a diagnosis of ADHD and ODD, or even testing for ASD, the therapeutic alliance may undergo threats, as on one hand the professionals may feel that they are at a gridlock, while the family feeling confused might disengage. In this context the systemic therapist is challenged not to be roped into power struggles by validating differences and working towards increasing perspective taking, while focusing on the importance of coordinating efforts for the benefit of the child.

The systemic psychotherapist needs to encourage a culture of working together based on principles of collective responsibility. This is made possible by holding a 'bothand' strategy rather than an 'either-or' dichotomous thinking approach especially in the context of blaming that can occur between family and school. A systemic-relational approach in multi-professional meetings can open the diversity of the narrative and thus releases pressure off the child, who often ends up being the bearer of problematic behaviour. This approach is in line with collaborative settings such as the open dialogue, suggested by Seikkula (2002). Systemic psychotherapists are uniquely suited to support relationships between families and schools. The therapeutic alliance formed with the two most influential systems in a child's life can create lasting change for young people and their families. For instance, the therapist may act as a coach by setting up role-plays with the parents to rehearse encounters with school professionals. At the same time a therapist can 
be collaborating with school personnel to help them hold a more open attitude with the family and ensure that the student has a primary attachment figure within the school for any arising matters. Results of this study show that the school system, has to be treated by the systemic psychotherapist like a client, with whom alliances need to be formed to ensure collaboration. In the context of family therapy work and relational trauma issues, the school can play a vital part in offering the child safety and security.

\section{Limitations of the Study}

The findings should be viewed in light of the following limitations:

Since the family were still involved in the therapeutic process the family members may have felt the need to portray the therapist and their relationships in a positive light. Nonetheless the rich data collected in the live-observations would not have been possible if the research was carried out retrospectively.

An objective measure of the alliance, such as the SOFTA could have strengthened the research design. Even if used in a retrospective fashion such a measure could have been helpful as another source of data.

The data collection took place in the engagement stage of therapy. It would have been interesting to study the development of the alliance at other stages of the process, especially at the end of therapy.

\section{Suggestions for Future Research}

Future research should continue to give a voice to young family members participating in systemic psychotherapy. It would be interesting to research what the therapeutic alliance is like for children over the course of therapy, possibly integrating their views through diary logs that would show how their experience changes over time.

The same research design could also be replicated recruiting more families to bring to light themes of similarities and differences across cases. Integrating an objective measure of the therapeutic alliance such as the SOFTA, could strengthen the research design.

It would also be interesting to unpack further the benefits and drawbacks of including children in family processes. We believe that it is a dilemma that many systemic practitioners who like us have a passion for working with children may face.
Author contributions Conception or design of the work [Maria Lisa, Angela], Data collection [Maria Lisa], Data analysis and interpretation [Maria Lisa, Angela], Drafting the article [Maria Lisa], Critical revision of the article [Angela], Final approval of the version to be published [Maria Lisa, Angela].

Funding This study is partially funded by the Endeavour Scholarship Scheme (Malta). Scholarships are part-financed by the European Union- European Social Fund (ESF)- Operational Programme II- Cohesion Policy 2014-2020 "Investing in human capital to create more opportunities and promote the well-being of society."

Data Availability The data that support the findings of this study are available on request from the corresponding author. The data are not publicly available due to the fact that information could compromise the privacy of research participants.

Code Availability Not applicable.

\section{Declarations}

Conflict of interest The authors have no relevant financial or non-financial interests to disclose.

Ethical Approval Ethical approval was sought from the University of Malta's Department of Family Studies- and Faculty for Social Wellbeing- Research Ethics Board. The Foundation for Social Welfare Services (FSWS) Research Ethics Committee.

Consent to Participate Informed consent was obtained from all individual participants included in the study.

Consent for Publication The authors affirm that participants provided informed consent.

\section{References}

Abela, A. (2016). Family life. In M. Briguglio \& M. Brown (Eds.), Sociology of the Maltese islands (pp. 18-46). Miller Publications.

Alexander, P. (2013). Relational trauma and disorganised attachment. In J. D. Ford \& C. A. Courtois. (Eds.), Treating complex traumatic stress disorders in children and adolescents, (pp.39-62). Guilford Press.

Anderson, H., \& Goolishian, H. A. (1988). Human systems as linguistic systems: preliminary and evolving ideas about the implications for clinical theory. Family Process, 27(4), 371-393. https://doi.org/ 10.1111/j.1545-5300.1988.00371.x

Andolfi, M. (2016). How to give voice to children in family therapy. In M. Borcsa \& P. Stratton (Eds.), Origins and originality in family therapy and systemic practice (pp. 143-167). Springer.

Balestra, F. (2017). Analysing the relational components of systemic family therapy through the lenses of self-positions and therapeutic alliance: an exploratory study. Journal of Family Therapy, 39(3), 310-328. https://doi.org/10.1111/1467-6427.12175

Benítez, J. L., Abascal, A., Garrido, M., \& Escudero, V. (2019). Building an expanded therapeutic alliance: a task analysis with families trapped in parental-adolescent conflict. Family Process. https:// doi.org/10.1111/famp.12435

Berryhill, M. B., \& Vennum, A. (2015). Joining forces: bringing parents and schools together. Contemporary Family Therapy, 37(4), 351-363. https://doi.org/10.1007/s10591-015-9357-3 
Brown, J. (2008). We don't need your help, but will you please fix our children. Australian and New Zealand Journal of Family Therapy, 29(02), 61-69. https://doi.org/10.1375/anft.29.2.61

Campbell, A. F., \& Simmonds, J. G. (2011). Therapist perspectives on the therapeutic alliance with children and adolescents. Counselling Psychology Quarterly, 24(3), 195-209. https://doi.org/10. 1080/09515070.2011.620734

Cloitre, M., Cohen, L. R., \& Scarvalone, P. (2002). Understanding revictimization among childhood sexual abuse survivors: an interpersonal schema approach. Journal of Cognitive Psychotherapy, 16(1), 91-111. https://doi.org/10.1891/jcop.16.1.91.63698

Creswell, J. W. (2012). Qualitative inquiry and research design: Choosing among five approaches (3rd ed). Sage.

Dallos, \& Vetere, A. (2009). Systemic therapy and attachment narratives: Applications in a range of clinical settings. Routledge.

Dallos, R., \& Vetere, A. (2005). Researching psychotherapy and counselling. Open University Press.

Desmond, K. J., Kindsvatter, A., Stahl, S., \& Smith, H. (2015). Using creative techniques with children who have experienced trauma. Journal of Creativity in Mental Health, 10(4), 439-455. https:// doi.org/10.1080/15401383.2015.1040938

DeVet, K. A., Kim, Y. J., Charlot-Swilley, D., \& Ireys, H. T. (2003). The therapeutic relationship in child therapy: perspectives of children and mothers. Journal of Clinical Child and Adolescent Psychology, 32(2), 277-283. https://doi.org/10.1207/S15374424J CCP3202 13

Diamond, G. S., \& Liddle, H. A. (1999). Transforming negative parent-adolescent interactions: from impasse to dialogue. Family Process, 38(1), 5-26. https://doi.org/10.1111/j.1545-5300.1999. 00005

Eltz, M. J., Shirk, S. R., \& Sarlin, N. (1995). Alliance formation and treatment outcome among maltreated adolescents. Child Abuse \& Neglect, 19(4), 419-431. https://doi.org/10.1016/0145-2134(95) 00008-V

Escudero, V., \& Friedlander, M. L. (2017). Therapeutic alliances with families: Empowering clients in challenging cases. Springer.

Escudero, V. (2016). Guest editorial: the therapeutic alliance from a systemic perspective: editorial. Journal of Family Therapy, 38(1), 1-4. https://doi.org/10.1111/1467-6427.12110

Freeman, M. (2003). Identity and difference in narrative inquiry. Narrative Inquiry, 13(2), 331-346. https://doi.org/10.1075/ni.13.2. 06 fre

Friedlander, M. L., Escudero, V., Horvath, A. O., Heatherington, L., Cabero, A., \& Martens, M. P. (2006). System for observing family therapy alliances: a tool for research and practice. Journal of Counselling Psychology, 53(2), 214-225. https://doi.org/10.1037/ 0022-0167.53.2.214

Friedlander, M. L., Escudero, V., Welmers-van de Poll, M. J., \& Heatherington, L. (2018). Meta-analysis of the alliance-outcome relation in couple and family therapy. Psychotherapy, 55(4), 356-371. https://doi.org/10.1037/pst0000161

Geertz, C. (1988). Works and lives: The anthropologist as author. University Press.

Guba, E. G. (1981). Criteria for assessing the trustworthiness of naturalistic inquiries. ECTJ, 29(2), 75-91. https://doi.org/10.1007/ BF02766777

Jensen, P. (2012). Family therapy, personal life and therapeutic practice. The map of relational resonance as a language for analysing psychotherapeutic processes. Human Systems: The Journal of Therapy, Consultation and Training, 23 (1), 68-87. http://hdl. handle.net/11250/194954

Lobatto, W. (2002). Talking to children about family therapy: a qualitative research study. Journal of Family Therapy, 24(3), 330-343. https://doi.org/10.1111/1467-6427.00221
McCormack, C. (2000). From interview transcript to interpretive Part 1: viewing the transcript through multiple lenses. Field Methods, 12(4), 282-296. https://doi.org/10.1177/1525822X0001200402

McCormack, C. (2004). Storying stories: a narrative approach to indepth interview conversations. International Journal of Social Research Methodology, 7(3), 219-236. https://doi.org/10.1080/ 13645570210166382

McIlwaine, F., \& O'Sullivan, K. (2015). 'Riding the wave': working systemically with traumatised families. Australian and New Zealand Journal of Family Therapy, 36(3), 310-324. https://doi.org/ 10.1002/anzf.1114

McLeod, J. (2010). Case study research in counselling and psychotherapy. Sage.

Nunez, L., Midgley, N., Capella, C., Alamo, N., Mortimer, R., \& Krause, M. (2021). The therapeutic relationship in child psychotherapy: integrating the perspectives of children, parents and therapists. Psychotherapy Research. https://doi.org/10.1080/10503 307.2021.1876946

O'Reilly, M. (2015). 'We're here to get you sorted': parental perceptions of the purpose, progression and outcomes of family therapy. Journal of Family Therapy, 37(3), 322-342. https://doi.org/10. 1111/1467-6427.12004

O'Reilly, M., \& Lester, J. N. (2016). Building a case for good parenting in a family therapy systemic environment: resisting blame and accounting for children's behaviour. Journal of Family Therapy, 38(4), 491-511. https://doi.org/10.1111/1467-6427.12094

Onnis, L. (2016). From pragmatics to complexity: Developments and perspective of systemic psychotherapy. In M. Borcsa \& P. Stratton (Eds.), Origins and originality in family therapy and systemic practice (pp. 13-25). Springer.

Pearlman, L. A., \& Courtois, C. A. (2005). Clinical applications of the attachment framework: relational treatment of complex trauma. Journal of Traumatic Stress, 18(5), 449-459. https://doi.org/10. 1002/jts. 20052

Perkins, S. N., Glass, V. Q., \& D'Aniello, C. (2019). It's all about the balance: therapists' experience of systemic alliance development. Contemporary Family Therapy. https://doi.org/10.1007/ s10591-019-09500-1

Riessman, C. K. (2008). Narrative methods for the human sciences. Sage.

Sammut Scerri, C., Vetere, A., Abela, A., \& Cooper, J. (2017). Intervening after violence: Therapy for couples and families. Springer.

Schwandt, T. A. (2014). The SAGE Dictionary of Qualitative Inquiry. Sage.

Seikkula, J. (2002). Open dialogues with good and poor outcomes for psychotic crises: examples from families with violence. Journal of Marital and Family Therapy, 28(3), 263-274. https://doi.org/ 10.1111/j.1752-0606.2002.tb01183.x

Sheridan, M., Peterson, B. D., \& Rosen, K. H. (2010). The experiences of parents of adolescents in family therapy: a qualitative investigation. Journal of Marital and Family Therapy, 36(2), 144-157. https://doi.org/10.1111/j.1752-0606.2010.00193.x

Shirk, S. R., Karver, M., \& Brown, R. (2011). The alliance in child and adolescent psychotherapy. Psychology Faculty Publications, 48(1), 17-24. https://doi.org/10.1037/a0022181

Simon, G. (2018) Eight criteria for quality in systemic practitioner research. Murmurations: Journal of Transformative Systemic Practice 1 (2): 40-62 Doi: https://doi.org/10.28963/1.2.5

Sprenkle, D. H., \& Blow, A. J. (2004.). Common factors and our sacred models. Journal of Marital and Family Therapy, 30(2), 113-129. https://doi.org/10.1111/j.1752-0606.2004.tb01228.x

Stake, R. E. (2005). Qualitative case studies. In N. K. Denzin \& Y. S. Lincoln (Eds.), The Sage handbook of qualitative research (pp. 443-466). Sage.

Stith, S. M., Rosen, K. H., McCollum, E. E., Coleman, J. U., \& Herman, S. A. (1996). The voices of children: preadolescent 
children's experiences in family therapy. Journal of Marital and Family Therapy, 22(1), 69-86. https://doi.org/10.1111/j.17520606.1996.tb00188.x

Thompson, S. J., Bender, K., Lantry, J., \& Flynn, P. M. (2007). Treatment engagement: building therapeutic alliance in homebased treatment with adolescents and their families. Contemporary Family Therapy, 29, 39-55. https://doi.org/10.1007/ s10591-007-9030-6

Van Nieuwenhove, K., \& Meganck, R. (2019). Interpersonal features in complex trauma etiology, consequences, and treatment. Journal of Aggression, Maltreatment \& Trauma, 28(8), 903-928. https:// doi.org/10.1177/1524838009339757

Willis, A. B., Walters, L. H., \& Crane, D. R. (2014). Assessing playbased activities, child talk, and single session outcome in family therapy with young children. Journal of Marital and Family Therapy, 40(3), 287-301. https://doi.org/10.1111/jmft.12048
Publisher's Note Springer Nature remains neutral with regard to jurisdictional claims in published maps and institutional affiliations. 